\title{
Characterization of Physical, Thermal and Spectral Properties of Biofield Treated Date Palm Callus Initiation Medium
}

\author{
Mahendra Kumar Trivedi ${ }^{1}$, Alice Branton ${ }^{1}$, Dahryn Trivedi ${ }^{1}$, Gopal Nayak ${ }^{1}$, \\ Rakesh Kumar Mishra ${ }^{2}$, Snehasis Jana ${ }^{2, *}$ \\ ${ }^{1}$ Trivedi Global Inc., Henderson, USA \\ ${ }^{2}$ Trivedi Science Research Laboratory Pvt. Ltd., Bhopal, Madhya Pradesh, India
}

Email address:

publication@trivedisrl.com (S. Jana)

\section{To cite this article:}

Mahendra Kumar Trivedi, Alice Branton, Dahryn Trivedi, Gopal Nayak, Rakesh Kumar Mishra, Snehasis Jana. Characterization of Physical, Thermal and Spectral Properties of Biofield Treated Date Palm Callus Initiation Medium. International Journal of Nutrition and Food Sciences. Vol. 4, No. 6, 2015, pp. 660-668. doi: 10.11648/j.ijnfs.20150406.20

\begin{abstract}
The date palm is mainly cultivated for the production of sweet fruit. Date palm callus initiation medium (DPCIM) is used for plant tissue culture applications. The present work is intended to evaluate the impact of Mr. Trivedi's biofield energy treatment on physical, thermal and spectral properties of the DPCIM. The control and treated DPCIM were evaluated by various analytical techniques such as X-ray diffraction (XRD), differential scanning calorimetry (DSC), thermogravimetric analysis (TGA), Fourier transform infrared (FT-IR) spectroscopy, particle size analyzer (PSA), surface area analyzer and ultra violet-visible spectroscopy (UV-vis) analysis. The XRD analysis revealed a decrease in intensity of XRD peaks of the treated sample as compared to the control. The crystallite size of the treated DPCIM $(81.02 \mathrm{~nm})$ was decreased with respect to the control sample $(84.99 \mathrm{~nm})$. The DSC analysis showed a slight decrease in melting temperature of the treated sample. Additionally, the latent heat of fusion of treated sample was changed by $45.66 \%$ as compared to the control sample. The TGA analysis showed an increase in onset degradation temperature of the treated sample $\left(182^{\circ} \mathrm{C}\right)$ as compared to the control sample $\left(142^{\circ} \mathrm{C}\right)$. This indicated the increase in thermal stability of the treated DPCIM. PSA results demonstrated an increase in average particle size $\left(\mathrm{d}_{50}\right)$ and size showed by $99 \%$ of particles $\left(\mathrm{d}_{99}\right)$ by 19.2 and $40.4 \%$, respectively as compared to the control sample. The surface area analyzer showed a decrease in surface area of treated DPCIM by $13.4 \%$, which was well supported by the particle size results. UV spectra of the treated sample showed the disappearance of absorption peak $261 \mathrm{~nm}$ in treated sample as compared to the control. Overall, the result showed that biofield energy treatment has a paramount influence on physical, thermal and spectral properties of DPCIM. Therefore, it is assumed that biofield treated DPCIM could be used as a better medium for plant tissue culture applications.
\end{abstract}

Keywords: Biofield Energy Treatment, Date Palm Callus Initiation Medium, X-ray Diffraction, Thermal Analysis, Particle Size Analysis, Surface Area Analysis

\section{Introduction}

Date palm or Phoenix dactylifera is a flowering plant belongs to the family Arecaceae, cultivated for its sweet fruits [1]. The species is widely cultivated and naturalized in many tropical and subtropical regions worldwide. Dates have been used as staple food in the Middle East and Indus valley [2, 3]. Date palms have numerous health benefits as they produce antioxidant flavonoids such as $\beta$-carotene, lutein, and zeta xanthin, which have the ability to protect the cells and structures in the body from harmful effects of oxygen free radicals. Additionally, it has anticancer, anti-inflammatory and anti-hyperlipidemic activities [4]. Date palm callus initiation medium (DPCIM) is used as tissue culture medium for microbiology applications. The ingredients of this medium are presented in Table 1 [5]. Micropropagation is a true to type propagation of a selected genotype using in vitro culture techniques [6]. Plant tissue culture technology provides a mean for a rapid, large-scale multiplication of plants and has been used for the propagation of crop and ornamental plants [7]. Additionally, DPCIM can also be used for agriculture 
applications for improving crop production and pathogen elimination [7].

Sterilization is a process that removes all form of living organisms such as prions, viruses, fungi, bacteria, etc. from the tissue culture medium. In general autoclaving is used for sterilizing the media [8]. It was reported previously that heat treatment of complex culture medium may result in nutrient destruction either by direct thermal degradation or by reaction between the components [9]. Hence, an alternative strategies should be designed which can avoid these shortcomings and maintain the nutrient value of the culture medium. Recently, biofield treatment a plausible approach was considered as an alternative method for physicochemical modification of organic compounds [10], pharmaceutical drugs [11], and polymers [12].

The prestigious National Institute of Health $(\mathrm{NIH}) /$ The National Centre for Complementary and Alternative Medicine (NCCAM), permits the use of Complementary and Alternative Medicine (CAM) therapies as an alternative in the healthcare field. It was also reported that majority of patients use alternative therapies in combination with conventional medicine [13]. Recently, an area of alternative medicine that is particularly amenable to use in a complementary way is called biofield energy therapy [14]. Therefore, it is suggested that human beings have the ability to harness the energy from the surrounding environment/Universe and can transmit into any object (living or non-living) around the Globe. The object(s) always receive the energy and responding in a useful manner that is called biofield energy.

Table 1. Ingredients of the date palm callus initiation medium.

\begin{tabular}{lll}
\hline S. No. & Ingredient & Milligram/Litre \\
\hline 1 & Potassium nitrate & 1900.00 \\
2 & Ammonium nitrate & 1650.00 \\
3 & Calcium chloride. $2 \mathrm{H}_{2} \mathrm{O}$ & 440.00 \\
4 & Magnesium sulfate & 180.69 \\
5 & Potassium phosphate monobasic & 170.00 \\
6 & Sodium phosphate monobasic & 117.20 \\
7 & Manganese sulfate & 180.69 \\
8 & Boric acid & 6.20 \\
9 & Potassium iodide & 0.83 \\
10 & Molybdic acid $\left(\right.$ sodium salt).2 $\mathrm{H}_{2} \mathrm{O}$ & 0.25 \\
11 & Zinc sulfate. $7 \mathrm{H}_{2} \mathrm{O}$ & 8.60 \\
12 & Copper sulfate $5 \mathrm{H}_{2} \mathrm{O}$ & 0.025 \\
13 & Cobalt chloride6 $\mathrm{H}_{2} \mathrm{O}$ & 0.025 \\
14 & Ferrous sulfate $7 \mathrm{H}_{2} \mathrm{O}$ & 27.80 \\
15 & EDTA disodium salt $2 \mathrm{H}_{2} \mathrm{O}$ & 37.30 \\
16 & Myo-inositol & 100.00 \\
17 & Thiamine hydrochloride & 0.40 \\
18 & 2,4-Dichlorophenoxy acetic acid & 100.00 \\
19 & 2IP & 3.00 \\
20 & Activated charcoal & 3000.00 \\
21 & Sucrose & $30,000.00$ \\
22 & Agar & 8000.00 \\
\hline
\end{tabular}

Mr. Mahendra Kumar Trivedi is a well-known healer of biofield energy therapy who can alter the characteristics in various research fields such as biotechnology [15] and microbiology [16]. This unique biofield energy treatment is also known as The Trivedi Effect ${ }^{\circledR}$. Hence, by capitalizing on the unique biofield energy treatment and properties of DPCIM as plant tissue culture medium, this research work was pursued to investigate the impact of biofield energy treatment on the physical, thermal and spectral properties of this compound. The control and treated samples were analyzed for their physicochemical properties using various analytical techniques such as X-ray diffraction, differential scanning calorimetry, thermogravimetric analysis, Fourier transform infrared spectroscopy, particle size analysis, surface area analysis and ultra violet-visible spectroscopy analysis.

\section{Materials and Methods}

Date Palm Callus Initiation Medium (DPCIM) was procured from HiMedia Laboratories, India. The sample was divided into two parts; one was kept as the control sample while the other was subjected to Mr. Trivedi's unique biofield energy treatment and coded as treated sample. The treated sample was in sealed pack and handed over to Mr. Trivedi for biofield energy treatment under laboratory condition. Mr. Trivedi gave the energy treatment through his unique energy transmission process to the treated samples without touching it.

\subsection{X-ray Diffraction (XRD)}

XRD analysis of control and treated DPCIM was evaluated using X-ray diffractometer system, Phillips, Holland PW 1710 which consist of a copper anode with nickel filter. XRD system had a radiation of wavelength $1.54056 \AA$. The average crystallite size $(G)$ was computed using formula:

$$
\mathrm{G}=\mathrm{k} \lambda /(\mathrm{b} \operatorname{Cos} \theta)
$$

Here, $\lambda$ is the wavelength of radiation used, $b$ is full-width half-maximum (FWHM) of peaks and $\mathrm{k}$ is the equipment constant $(=0.94)$. Percentage change in average crystallite size was calculated using following formula:

Percentage change in crystallite size $=\left[\left(\mathrm{G}_{\mathrm{t}}-\mathrm{G}_{\mathrm{c}}\right) / \mathrm{G}_{\mathrm{c}}\right] \times 100$

Where, $\mathrm{G}_{\mathrm{c}}$ and $\mathrm{G}_{\mathrm{t}}$ are denoted as crystallite size of control and treated powder samples respectively.

\subsection{Differential Scanning Calorimetry (DSC)}

The control and treated DPCIM samples were analyzed using Pyris-6 Perkin Elmer DSC at a heating rate of $10^{\circ} \mathrm{C} / \mathrm{min}$, and the air was purged at a flow rate of $5 \mathrm{~mL} / \mathrm{min}$. The predetermined amount of sample was kept in an aluminum pan and closed with a lid. A reference sample was prepared using a blank aluminum pan. The percentage change in latent heat of fusion was calculated using following equations:

$$
\begin{aligned}
& \text { \% change in Latent heat of fusion } \\
& =\frac{\left[\Delta \mathrm{H}_{\text {Treated }}-\Delta \mathrm{H}_{\text {Control }}\right]}{\Delta \mathrm{H}_{\text {Control }}} \times 100
\end{aligned}
$$

Where, $\Delta \mathrm{H}_{\text {Control }}$ and $\Delta \mathrm{H}_{\text {Treated }}$ are the latent heat of fusion of control and treated samples, respectively. 


\subsection{Thermogravimetric Analysis-Differential Thermal Analysis (TGA-DTA)}

A Mettler Toledo simultaneous TGA and differential thermal analyzer (DTA) was used to investigate the thermal stability of control and treated DPCIM samples. The rate of heating was $5^{\circ} \mathrm{C} / \mathrm{min}$, and samples were heated in the range of room temperature to $400^{\circ} \mathrm{C}$ under air atmosphere.

\subsection{FT-IR Spectroscopy}

The FT-IR spectra were recorded on Shimadzu's Fourier transform infrared spectrometer (Japan) with the frequency range of $4000-500 \mathrm{~cm}^{-1}$.

\subsection{Particle Size Analysis}

The average particle size and particle size distribution were analyzed by using Sympetac Helos-BF Laser Particle Size Analyzer with a detection range of 0.1 micrometer to 875 micrometer. Average particle size $\mathrm{d}_{50}$ and $\mathrm{d}_{99}$ size exhibited by $99 \%$ of powder particles were computed from laser diffraction data table. The $\mathrm{d}_{50}$ and $\mathrm{d}_{99}$ values were calculated by the following formula:

Percentage change in $\mathrm{d}_{50}$ size $=100 \times\left(\mathrm{d}_{50}\right.$ treated $-\mathrm{d}_{50}$ control $) /$ $\mathrm{d}_{50}$ control

Percentage Change in $\mathrm{d}_{99}$ size $=100 \times\left(\mathrm{d}_{99}\right.$ treated $-\mathrm{d}_{99}$ control $) /$ $\mathrm{d}_{99}$ control

\subsection{Surface Area Analysis}

The surface area of DPCIM was characterized using surface area analyzer, Smart SORB 90 BET, which had a detection range of $0.1-100 \mathrm{~m}^{2} / \mathrm{g}$.

\subsection{UV-Vis Spectroscopic Analysis}

A Shimadzu UV-2400 PC series spectrophotometer with 1 $\mathrm{cm}$ quartz cell and a slit width of $2.0 \mathrm{~nm}$ was used to obtain the UV spectra of the control and treated DPCIM samples. The spectroscopic analysis was carried out using the wavelength in the range of $200-400 \mathrm{~nm}$ and methanol was used as a solvent.

\section{Results and Discussions}

\subsection{XRD Study}

$\mathrm{XRD}$ is a non-destructive analysis technique that is used to evaluate the crystalline nature of the materials. The XRD diffractogram of control and treated DPCIM are presented in Figure 1. The XRD diffractogram of control and treated samples showed intense peaks that were due to their crystalline nature. XRD diffractogram of control sample showed peaks at $2 \theta$ equal to $11.66^{\circ}, 12.73^{\circ}, 13.14^{\circ}, 15.52^{\circ}$, $16.72^{\circ}, 18.84^{\circ}, 19.57^{\circ}, 20.37^{\circ}, 20.82^{\circ}, 22.03^{\circ}, 23.51^{\circ}, 24.74^{\circ}$, $25.21^{\circ}, 29.38^{\circ}$ and $30.99^{\circ}$. Additionally, the treated sample showed the presence of XRD peaks at $2 \theta$ equal to $11.67^{\circ}$, $12.68^{\circ}, 13.14^{\circ}, 15.46^{\circ}, 16.71^{\circ}, 18.80^{\circ}, 19.56^{\circ}, 20.35^{\circ}, 20.81^{\circ}$, $22.00^{\circ}, 23.50^{\circ}, 24.72^{\circ}, 25.18^{\circ}, 29.35^{\circ}$ and $30.97^{\circ}$. It was observed that $2 \theta$ angle (Braggs angle) of XRD peaks of treated sample were decreased at $2 \theta$ equals to $12.73^{\circ} \rightarrow 12.68^{\circ}$, $15.52^{\circ} \rightarrow 15.46^{\circ}$ as compared to the control sample. Additionally, the result suggested the decrease in intensity of XRD peaks of treated sample as compared to the control. It was reported that atoms undergo thermal vibrations about their means positions even at the absolute zero temperature and amplitude of this vibration increase with elevation in temperature. The increase in temperature causes thermal vibration of atoms as a result unit cell may expand, causing changes in plane spacing $d$ and thus, in the $2 \theta$ positions of XRD peaks [17]. Additionally, this might cause a decrease in intensity of diffraction peaks. Thus, it is assumed here that biofield treatment may provide the thermal energy that led to increase in the unit cell, changes in plane spacing, and this ultimately decreases the intensity of the XRD peaks of the treated sample. The crystallite size was computed using the well-known Scherrer's formula and data are presented in Figure 2. The crystallite size of the control sample was 84.99 $\mathrm{nm}$, and it decreased up to $81.02 \mathrm{~nm}$ in the treated sample. The results suggested $4.67 \%$ decrease in crystallite size of the treated DPCIM as compared to the control sample. Additionally, researchers have also shown that occurrence of micro strain causes a decrease in crystallite size of the materials. Zhang et al. showed that presence of strain and increase atomic displacement from their ideal lattice positions causes a reduction in crystallite size [18]. Moreover, Pavia-santos et al. also reported a uniform decrease in crystallite size with the increase in micro-strain [19]. Thus, it is assumed that biofield energy treatment may cause micro strain in treated DPCIM molecules that led to the rapid displacement of an atom from their original lattice positions and ultimately decreases the crystallite size.

\subsection{DSC Study}

DSC studies were conducted to get the insights about the thermal nature, i.e. melting temperature and latent heat of fusion of the samples. The DSC thermogram of the control sample showed (Figure 3) an endothermic peak at $156.93^{\circ} \mathrm{C}$, which was due to melting temperature of the control sample. This peak was perhaps due to the melting of the sucrose content in the sample [20]. The DSC thermogram of control sample showed another endothermic peak at around $172^{\circ} \mathrm{C}$ that may be associated with thermal decomposition of the sample. However, the treated sample also showed two endothermic transitions in the DSC thermogram. The first endothermic peak was due to melting temperature $\left(155.89^{\circ} \mathrm{C}\right)$ and the second peak was due to thermal decomposition $\left(166.66^{\circ} \mathrm{C}\right)$ of the treated sample. Hence, the results suggested no significant change in melting temperature of the treated sample as compared to the control.

The latent heat of fusion was obtained from the DSC thermogram of control and treated samples. It was reported that energy required to overcome the intermolecular interaction between molecules is known as potential energy. This potential energy is stored in the material during its phase change from solid to liquid form. The control sample showed 
a latent heat of fusion of $129.75 \mathrm{~J} / \mathrm{g}$ and it was decreased to $70.50 \mathrm{~J} / \mathrm{g}$ in the treated sample. The result suggested that latent heat of fusion was decreased by $45.66 \%$ as compared to the control. It is presumed that the treated sample may present in the high-energy state that led to an alteration in latent heat of fusion of the treated sample. Recently, it was reported that biofield treatment has caused an alteration in latent heat of fusion of indole [9].

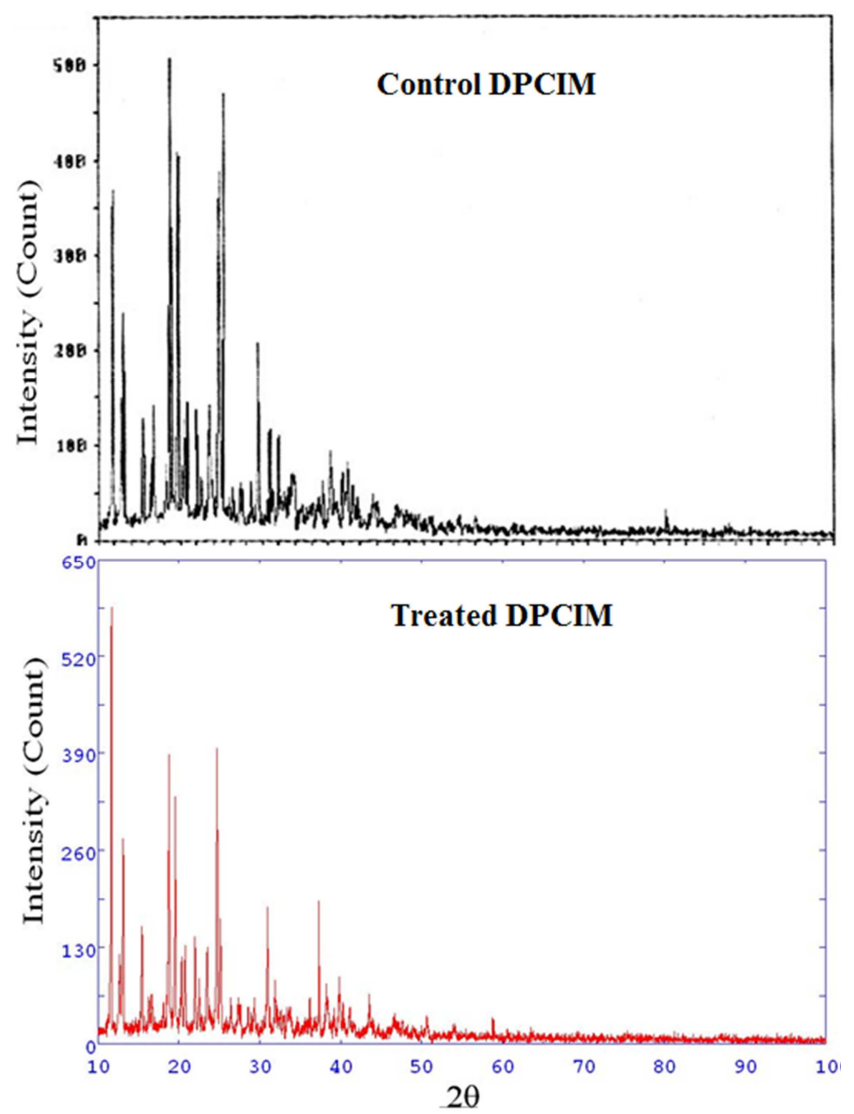

Fig. 1. XRD diffractograms of control and treated date palm callus initiation medium.

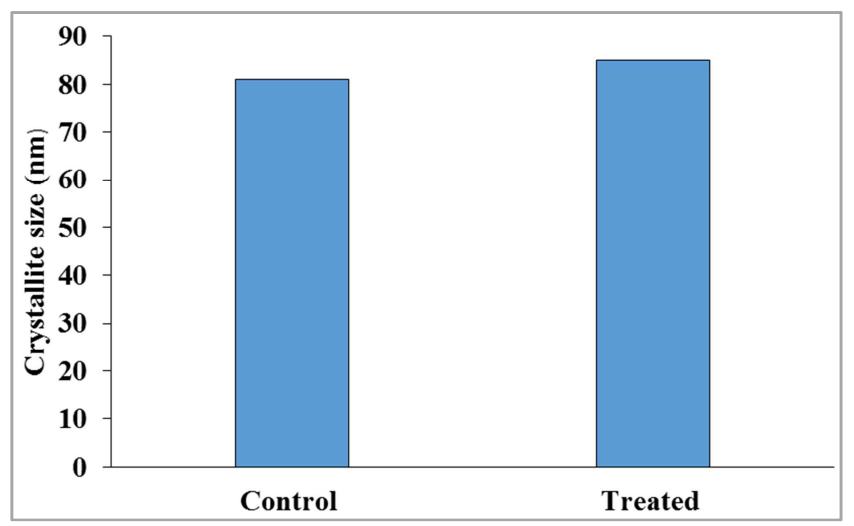

Fig. 2. Crystallite size of control and treated date palm callus initiation medium.
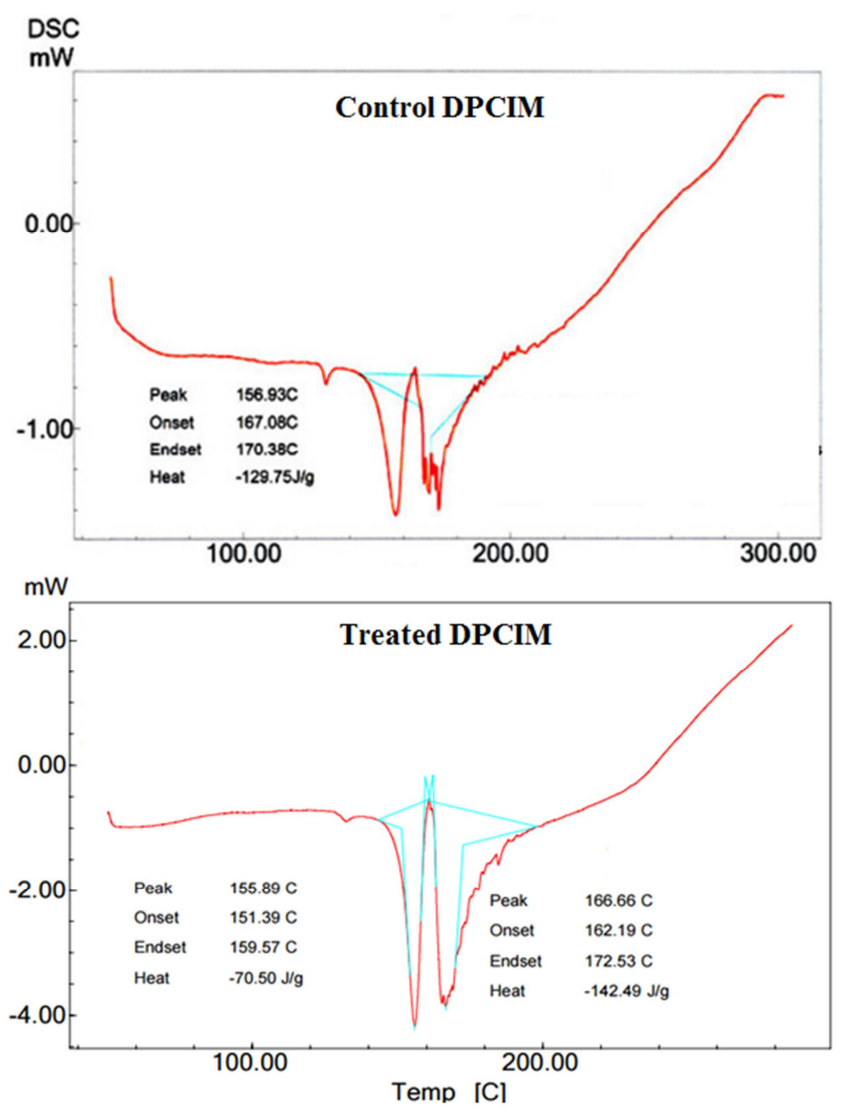

Fig. 3. DSC thermograms of control and treated date palm callus initiation medium.

\subsection{TGA Analysis}

TGA is mainly used to investigate the thermal properties such as a change in weight loss, oxidation, and thermal decomposition pattern of the materials. TGA thermogram of control and treated samples are presented in Figure 4. The TGA thermogram of control DPCIM showed three steps thermal degradation pattern. The first thermal degradation commenced at around $153^{\circ} \mathrm{C}$, and it was terminated at around $183^{\circ} \mathrm{C}$. The second thermal degradation was started at around $225^{\circ} \mathrm{C}$ and stopped at around $245^{\circ} \mathrm{C}$. Whereas, the third thermal degradation event was commenced at $285^{\circ} \mathrm{C}$ and terminated at $315^{\circ} \mathrm{C}$. The sample lost $15.17,7.63$ and $15.14 \%$ weight during the first, second and third thermal degradation event, respectively. Contrarily, the treated DPCIM sample showed two-step thermal decomposition. The first step was started at around $154^{\circ} \mathrm{C}$ and stopped at around $200^{\circ} \mathrm{C}$. However, the second thermal decomposition was started at $250^{\circ} \mathrm{C}$ and terminated at $380^{\circ} \mathrm{C}$. The treated sample lost around 11.19 and $32.12 \%$ weight during these two decomposition steps.

DTG thermogram of control and treated samples are shown in Figure 4. The DTG thermogram of control sample showed maximum weight loss occurred at 142, 196, 298 and $355^{\circ} \mathrm{C}$. The weight loss from $196^{\circ} \mathrm{C}$ was mainly due to the release of volatile matter and decomposition of the sample [21]. Whereas, the treated sample showed maximum weight loss at 182 and $299^{\circ} \mathrm{C}$. Thus, based on DTG curve the control sample 
showed the onset of thermal degradation at $142^{\circ} \mathrm{C}$, and it was increased to $182^{\circ} \mathrm{C}$ in the treated sample. This might be due to increase in thermal stability of the biofield treated sample as compared to control. Szabo et al. reported that thermal stability of doped poly (hexadecylthiophene) polymer was increased after $\gamma$-radiation treatment [22]. They proposed that $\gamma$-radiation treatment causes conformational changes and crosslinking in side alkyl groups that led to increase in the thermal stability of the polymer. Therefore, it is hypothesized that biofield energy treatment perhaps caused crosslinking and conformational changes in treated DPCIM molecules that led to increase in thermal stability. Moreover, the high thermal stability of the treated DPCIM might improve the stability of nutrients during sterilization as compared to the control.
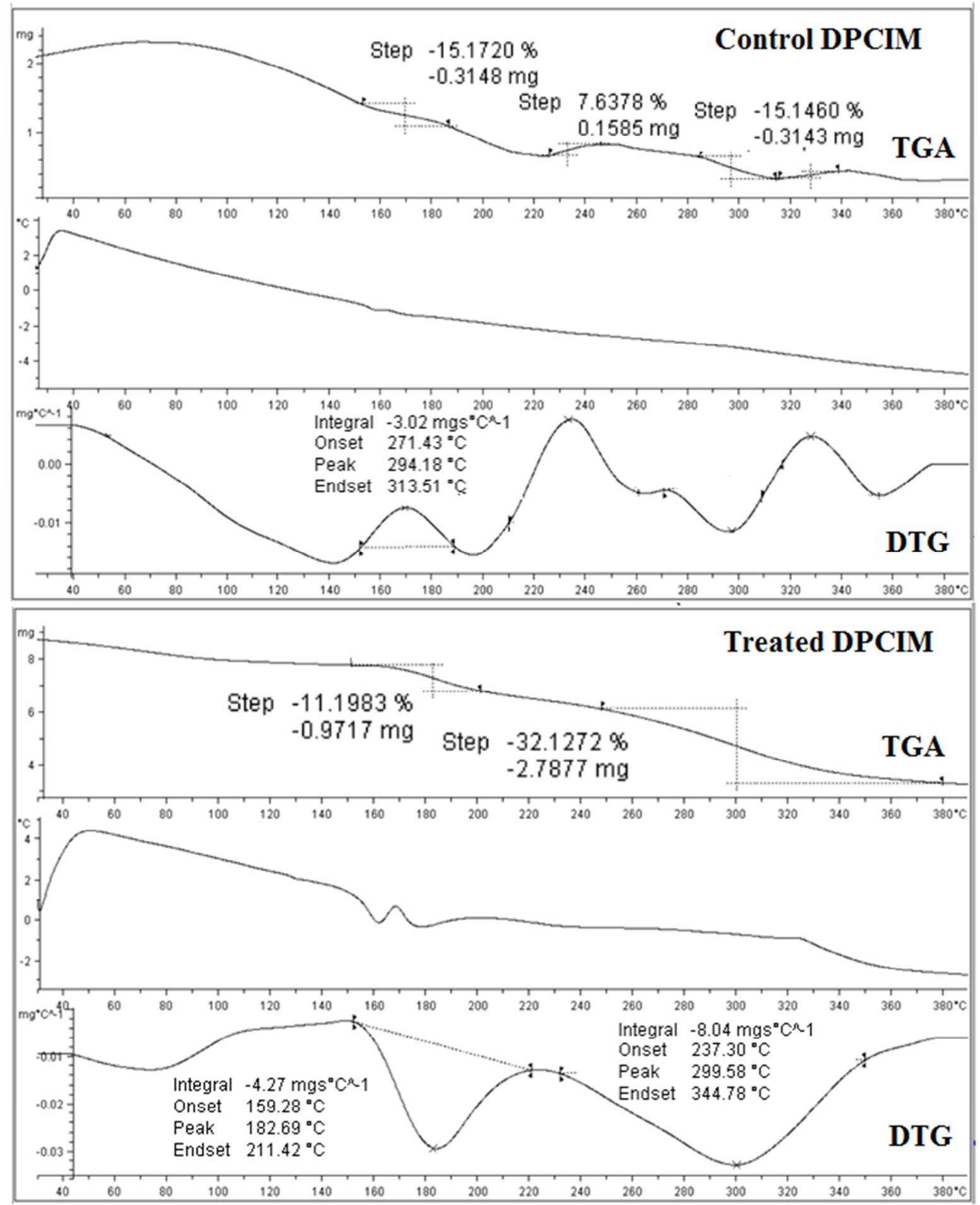

Temperature $\left({ }^{\circ} \mathrm{C}\right)$

Fig. 4. TGA thermograms of control and treated date palm callus initiation medium. 


\subsection{FT-IR Spectroscopy}

FT-IR spectrum of control and treated DPCIM are shown in Figure 5. The sample contains various ingredients such as sucrose, activated charcoal, EDTA, and agar. The FT-IR spectrum of the control DPCIM showed O-H stretching vibration peaks at 3384 , and $3332 \mathrm{~cm}^{-1}$. However, the treated sample showed $\mathrm{O}-\mathrm{H}$ stretching vibration peak at 3384 and $3336 \mathrm{~cm}^{-1}$. These broad hydroxyl peaks were mainly due to the presence of sucrose and agar in the control and treated samples. The vibration bands for $\mathrm{C}-\mathrm{H}$ stretching was observed at 2985 and $2941 \mathrm{~cm}^{-1}$ in the control and treated samples, respectively. The peak at $1768 \mathrm{~cm}^{-1}$ in control and treated samples were mainly due to lactone ring of the sucrose molecule. The IR peak observed at 1635 , and $1672 \mathrm{~cm}^{-1}$ were attributed to the $\mathrm{C}=\mathrm{O}$ group of the EDTA or sucrose present in the control and treated samples. The vibration peaks at 1417 and $1419 \mathrm{~cm}^{-1}$ were due to $-\mathrm{CH}$ bending peaks in the control and treated samples, respectively. The IR peak observed at
$1380 \mathrm{~cm}^{-1}$ in the control sample, and $1379 \mathrm{~cm}^{-1}$ in treated DPCIM sample were attributed to $\mathrm{N}=\mathrm{O}$ group from the ammonium nitrate or potassium nitrate in the sample [23]. Similarly, the vibration peaks at $1344 \mathrm{~cm}^{-1}$ in control and 1348 $\mathrm{cm}^{-1}$ in treated sample were due to the sulfate $(\mathrm{S}=\mathrm{O})$ ions present in the samples [24]. Moreover, the peak at $1236 \mathrm{~cm}^{-1}$ in control and treated samples were due to $\mathrm{C}-\mathrm{C}$ stretching. The vibrational bands at 1060 and $1066 \mathrm{~cm}^{-1}$ were observed due to $\mathrm{C}-\mathrm{O}$ stretching in the control and treated sample, respectively. Additionally, the vibration peaks for metal halide and aromatic stretching were observed at $682 \mathrm{~cm}^{-1}$, and $860 \mathrm{~cm}^{-1}$ in the control sample. However, these peaks were observed at $686 \mathrm{~cm}^{-1}$ and $860 \mathrm{~cm}^{-1}$ in the treated sample. Overall, the result showed no significant change in IR peaks of the treated sample as compared to the control sample. It is assumed that biofield treatment had not influenced the dipole moment, and force constant of the treated DPCIM.

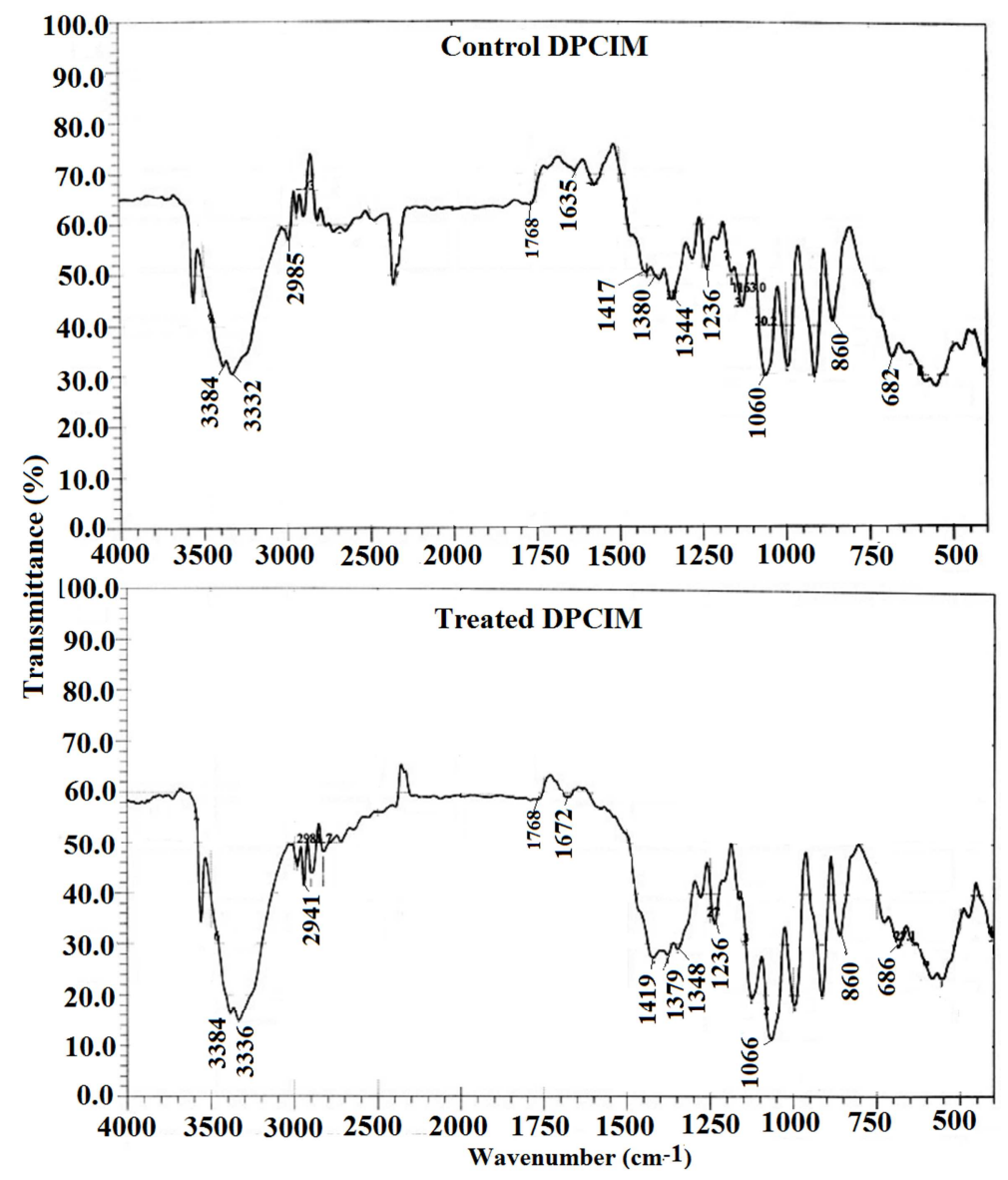

Fig. 5. FT-IR spectra of control and treated date palm callus initiation medium.

\subsection{Particle Size and Surface Area Analysis}

PSA was accomplished using a laser particle analyzer and data are reported in Figure 6. The average particle size $\left(d_{50}\right)$ of the control sample was $18.38 \mu \mathrm{m}$, and it was increased upto $21.9 \mu \mathrm{m}$ in the treated sample. However, the size exhibited by
$99 \%$ of particles $\left(d_{99}\right)$ of the control sample was $263.44 \mu \mathrm{m}$, and it was increased substantially to $369.78 \mu \mathrm{m}$ in the treated sample. The result suggested that $\mathrm{d}_{50}$ and $\mathrm{d}_{99}$ were increased by 19.2 and $40.4 \%$ respectively as compared to the control sample. It was reported that increase in annealing temperature increases the particle size of materials. For instance, Iqbal et al. 
reported that elevation in annealing temperature cause the particles to collide and coalesce to form bigger microparticles [25]. Zhang et al. also suggested that higher annealing temperature resulted in increased particle size of cerium-zirconium binary oxide nanoparticles [26]. Thus, we assume here that biofield energy treatment perhaps provided the thermal energy that causes collision and increase in particle size of treated DPCIM. Many reports suggested that higher water uptake of an organic product such as rice bran, mainly depends on its particle size [27-29]. It was envisaged that larger sized particles take up more water as compared to smaller particles [27]. Albers et al., in a research study showed that Farinograph water absorption also decreased with decreasing particle size [30]. Hence, bigger macroparticles are likely to show more water uptake and this property could improve its gelling properties. Thus, the treated sample might confer better properties as tissue culture medium.

The surface area of the control and treated sample was evaluated using BET analyzer. The surface area of the control sample was $28.49 \mathrm{~m}^{2} / \mathrm{g}$, and it was decreased to $24.68 \mathrm{~m}^{2} / \mathrm{g}$ in the treated sample. The result demonstrated $13.4 \%$ decrease in surface area of the treated sample as compared to the control. Researchers have shown that particle size is inversely proportional to surface area [31]. Hence, increase in particle size may cause a decrease in surface area and vice versa. Therefore, an increase in particle size of treated DPCIM sample caused a decrease in surface area as compared to the control.

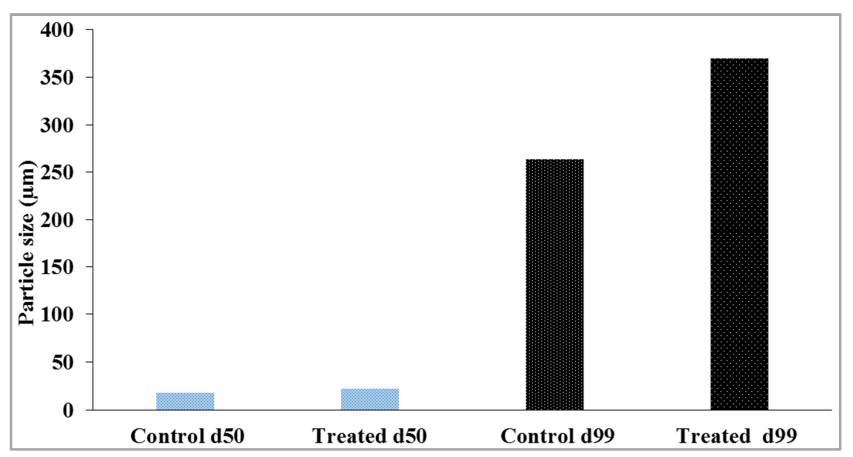

Fig. 6. Particle size $\left(d_{50}\right.$ and $\left.d_{99}\right)$ of control and treated date palm callus initiation medium.

\subsection{UV Visible Spectroscopy}

UV spectra of control and treated DPCIM samples are presented in Figure 7. The UV spectrum of control DPCIM showed absorption peaks at 210 and $261 \mathrm{~nm}$. However, the treated sample showed similar absorption peak at $210 \mathrm{~nm}$ as showed by the control sample. Nevertheless, the second absorption peak originally present at $261 \mathrm{~nm}$ in control was completely disappeared in the treated sample. According to Cinarli et al. the absorption peak appears in the region of 210-290 nm are mainly due to $\mathrm{n} \rightarrow \pi^{*}$ and $\pi-\pi^{*}$ transition of the aromatic rings [32]. Hence, it is assumed here that due to biofield treatment alterations occurred in electron i.e. bonding ( $\mathrm{n} \rightarrow \pi^{*}$ and $\pi \rightarrow \pi^{*}$ transition) from the ground state to excited state that led to a disappearance of the absorption peak in the treated sample.
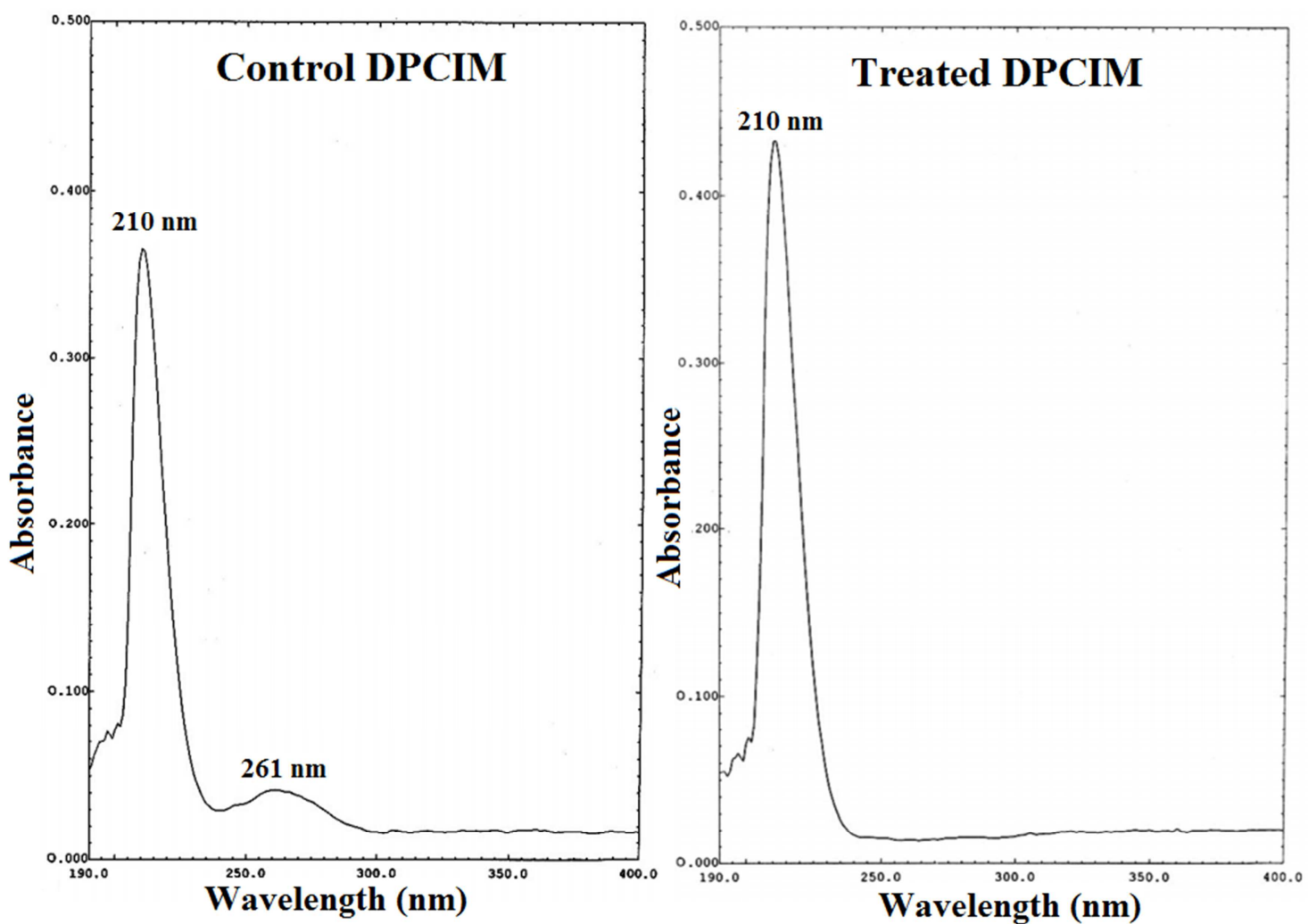

Fig. 7. UV spectra of control and treated date palm callus initiation medium. 


\section{Conclusions}

In summary, the XRD analysis showed a decrease in crystallite size of treated DPCIM as compared to the control sample. Moreover, the intensity of the XRD peaks of treated sample was decreased with respect to the control. It is assumed that presence of micro strain causes a decrease in crystallite size of the treated sample. The DSC analysis showed a decrease in latent heat of fusion of treated sample by $45.66 \%$ with respect to the control sample. It is assumed that treated sample might be present in the high-energy state that led to an alteration in latent heat of fusion of the sample. The TGA evaluation showed a substantial increase in onset temperature of treated sample $\left(182^{\circ} \mathrm{C}\right)$ as compared to the control sample $\left(142^{\circ} \mathrm{C}\right)$. The PSA analysis results showed a substantial increase in $d_{50}$ and $d_{99}$ by 19.2 and $40.4 \%$ respectively with respect to control. This was well supported by surface area result that was decreased by $13.4 \%$ in the treated sample. It is presumed that the high thermal stability and bigger particle size might improve DPCIM uses as tissue culture medium. Hence, it is presumed that biofield treated DPCIM could be used as a medium for plant tissue culture applications.

\section{Abbreviations}

XRD: X-ray diffraction; DSC: Differential scanning calorimetry; TGA: Thermogravimetric analysis; FT-IR: Fourier transform infrared; PSA: Particle size analyzer; UV-vis: Ultra violet-visible spectroscopy; DPCIM: Date palm callus initiation medium

\section{Acknowledgment}

The authors wish to thank all the laboratory staff of MGV Pharmacy College, Nashik for their kind assistance during handling the various instrument characterizations. The authors would also like to thank Trivedi Science, Trivedi Master Wellness and Trivedi Testimonials for their support during the work.

\section{References}

[1] https://en.wikipedia.org/wiki/Date_palm (Accessed on 7 October 2015).

[2] Biota of North America Project, Phoenix dactylifera. (Accessed on 7 October 2015).

[3] Flora of China, Phoenix dactylifera. (Accessed on 7 October 2015).

[4] Jain SM Health Benefits of date palm: Phytochemicals and their functions. https://tuhat.halvi.helsinki.fi/portal/files//Jain._Health_benefit s.pdf (Accessed on 7 October 2015).
[5] http://himedialabs.com/TD/PT084.pdf (Accessed on 9 October 2015).

[6] Al-Khayri JM (2007) Date palm phoenix dactylifera L. micropropagation. Protocols for micropropagation of woody trees and fruits. Springer, Netherlands.

[7] Hussey G (1983) In vitro propagation of horticulture and agricultural crops. Plant Biotechnology, Cambridge University, UK.

[8] Klacik S, Strickland B (2003) Central service technical manual. International association of healthcare central service material management, pp 83-100.

[9] Basu S, Pal A, Desai PK (2005) Quality control of culture media in a microbiology laboratory. Indian J Med Microbiol 23: 159-163.

[10] Trivedi MK, Tallapragada RM, Branton A, Trivedi A, Nayak G, et al. (2015) Biofield treatment: A potential strategy for modification of physical and thermal properties of indole. $\mathrm{J}$ Environ Anal Chem 2: 152.

[11] Trivedi MK, Patil S, Shettigar H, Bairwa K, Jana S (2015) Effect of biofield treatment on spectral properties of paracetamol and piroxicam. Chem Sci J 6: 98.

[12] Trivedi MK, Nayak G, Patil S, Tallapragada RM, Mishra R (2015) Influence of biofield treatment on physicochemical properties of hydroxyethyl cellulose and hydroxypropyl cellulose. J Mol Pharm Org Process Res 3: 126.

[13] Barnes PM, Powell-Griner E, McFann K, Nahin RL (2004) Complementary and alternative medicine use among adults: United States, 2002. Semin Integr Med 2: 54-71.

[14] Warber SL, Cornelio D, Straughn J, Kile G (2004) Biofield energy healing from the inside. J Altern Complement Med 10: 1107-1113.

[15] Patil SA, Nayak GB, Barve SS, Tembe RP, Khan RR (2012) Impact of biofield treatment on growth and anatomical characteristics of Pogostemon cablin (Benth.). Biotechnology 11: 154-162.

[16] Trivedi MK, Patil S, Shettigar H, Bairwa K, Jana S (2015) Phenotypic and biotypic characterization of Klebsiella oxytoca: An impact of biofield treatment. J Microb Biochem Technol 7: 202-205.

[17] Vinila VS, Jacob R, Mony A, Nair HG, Issac S, et al. (2014) XRD studies on nano crystalline ceramic superconductor $\mathrm{PbSrCaCuO}$ at different treating temperatures. Cryst Struct Theory Appl 3: 1-9.

[18] Zhang K, Alexandrov IV, Kilmametov AR, Valiev RZ, Lu K (1997) The crystallite-size dependence of structural parameters in pure ultrafine-grained copper. J Phys D Appl Phys 30: 3008-3015.

[19] Paiva-Santos CO, Gouveia H, Las WC, Varela JA (1999) Gauss-lorentz size-strain broadening and cell parameters analysis of $\mathrm{Mn}$ doped $\mathrm{SnO}_{2}$ prepared by organic route. Materials Structure 6: 111-115.

[20] Beckett ST, Francesconi MG, Geary PM, Mackenzie G, Maulny AP (2006) DSC study of sucrose melting. Carbohyd Res 341: 2591-2599.

[21] Babiker ME, Aziz ARA, Heikal M, Yusup S, Abakar M (2013) Pyrolysis characteristics of Phoenix dactylifera date palm seeds using thermo-gravimetric analysis (TGA). IJESD 4: 521-524. 
[22] Szabo L, Cik G, Lensy J (1996) Thermal stability increase of doped poly (hexadecylthiophene) by $\gamma$-radiation. Synt Met 78: 149-153.

[23] Miller FA, Wilkins CH (1952) Infrared spectra and characteristic frequencies of inorganic ions. Anal Chem 24: 1253-1294.

[24] Chaban GM, Huo WM, Lee TJ (2002) Theoretical study of infrared and Raman spectra of hydrated magnesium sulfate salts. J Chem Phys 117: 2532-2537.

[25] Iqbal MZ, Ali S, Mirza MA (2008) Effect of particle size on the structural and transport properties of $\mathrm{La}_{0.67} \mathrm{Ca}_{0.33} \mathrm{MNO}_{3}$ nanoparticles. JNSMAC 48: 51-63.

[26] Zhang F, Chen CH, Hanson JC, Robinson RD, Herman IP, et al. (2006) Phases in ceria-zirconia binary oxide (1-x) $\mathrm{CeO}_{2-}$ $\mathrm{xZrO}_{2}$ nanoparticles: The effect of particle Size. J Am Ceram Soc 89: 1028-1036.

[27] Albers S, Muchova Z, Fikselova M (2009) The effects of different treated brans additions on bread quality. Scienta Agriculturae Bohemica 40: 67-72.
[28] Auffret A, Ralet MC, Guillon F, Barry JL, Thibault JF (1994) Effect of grinding and experimental conditions on the measurement of hydration properties of dietary fibers. LWT-Food Sci Technol 27: 166-172.

[29] Zhang DC, Moore WR (1997) Effect of wheat bran particle size on dough rheological properties. J Sci of Food Agri 74: 490-496.

[30] Robertson JA, Eastwood MA (1981) An investigation of the experimental conditions which could affect water-holding capacity of dietary fiber. J Sci Food Agric 32: 819-825.

[31] Bendz D, Tuchsen PL, Christensen TH (2007) The dissolution kinetics of major elements in municipal solid waste incineration bottom ash particles. J Contam Hydrol 94: 178-194.

[32] Cinarli A, Gurbuz D, Tavman A, Birteksoz AS (2011) Synthesis, spectral characterizations and antimicrobial activity of some schiff bases of 4-chloro-2-aminophenol. Bull Chem Soc Ethiop 25: 407-417. 